\title{
3 A System Model for Crop Yield Potential as a Function of Herbicide Weed Control over Time
}

\subsection{Introduction}

Modelling is an all-encompassing term, which suggests anything from building a scaled representation of the system through to developing a rigorous mathematical analysis of the system's internal relationships. The ultimate purpose of the model is to produce a representation of the system (Wilson, 1988), which is easily understood, behaves in a similar way to the real system and can be more easily manipulated than the real system, in order to understand how things may change as inputs or time vary, which is referred to as "sensitivity analysis".

Often the system model is represented by mathematical relationships. There are two main strategies for determining these mathematical relationships. These are the empirical approach, which usually requires a statistical analysis of data from two or more system parameters (Walpole \& Myers, 1972) to evaluate the degree of cause and effect between these parameters, or the deterministic analysis, which employs a range of clearly defined and rigorous mathematical procedures to define the relationship between two or more system parameters.

In terms of mathematical effort, empirical relationships are generally easier to develop, but can not be stretched beyond the sampling range of the original data (Walpole \& Myers, 1972) from which the relationship was inferred. On the other hand, deterministic models are much harder to derive, requiring a sound knowledge of mathematic disciplines such as vectors, algebra and calculus, but the resulting equations tend to be much more robust than empirical relationships. Deterministic models can be extrapolated to explore more extreme cases.

System analysis can be applied to most agricultural systems to better understand their operation and optimise performance. System analysis usually includes the development of transfer functions (Åström \& Murray, 2012; Smith, 1976). Transfer functions are mathematical equations, involving various input variables or matrices, which relate the system's output to these system inputs. In the case of an agricultural cropping system the key output from the system is potential crop yield. Some crop ecology studies have demonstrated that competition from weeds can reduce the potential yield of some crops by 35\% to 55\% (Cathcart \& Swanton, 2003; Mondani, Golzardi, Ahmadvand, Ghorbani, \& Moradi, 2011).

Modern no-till cropping depends on herbicides for weed management; therefore, herbicide applications are an important system input. Unfortunately, herbicide resistance in many weed species is also becoming wide spread (Heap, 1997) and multiple herbicide resistances in several economically important weed species has been widely reported (Owen, Walsh, Llewellyn, \& Powles, 2007). In time, herbicide resistant weeds may result in significant yield reductions and grain contamination; 
therefore, this chapter derives a deterministic system transfer function, relating herbicide input to potential crop yield, in the presence of herbicide resistance, based on various ecological models published in literature.

\subsection{Derivation of Crop System Transfer Function for Herbicide Weed Management}

The effect of weed damage on crop yields can be described by equation (3.1) (Schmidt \& Pannell, 1996). The nomenclature of some parameters used in this chapter is outlined in Table 3.1, which is at the end of the chapter.

$$
Y=Y_{o}[1-D(R)]
$$

In equation (3.1), $D(R)$ is the damage function caused by a weed density of $R$, which represents the number of weeds that are recruited from the seed bank (plants $\mathrm{m}^{-1}$ of row). The Damage function can be described by the following equation (Cousens, Brain, O’Donovan, \& O’Sullivan, 1987):

$$
D(R)=\frac{I \cdot R}{100\left(e^{d}+\frac{I \cdot R}{A_{w}}\right)}
$$

Substituting equation (3.1) into equation (3.2) yields:

$$
Y=Y_{o}\left[1-\frac{I \cdot R}{100\left(e^{t}+\frac{I \cdot R}{A_{w}}\right)}\right]
$$

\subsection{Herbicide Weed Management}

Weed infestations will be made up of some resistant weeds $\left(R_{R}\right)$ and some weeds that can be easily controlled sby herbicides $\left(R_{S}\right)$, where the total weed population is the sum of these two components (i.e. $\mathrm{R}_{\mathrm{R}}-(1-S)$ and $\mathrm{R}_{\mathrm{S}}=S$ ). A typical kill function for a herbicide treatment is (Bosnić \& Swanton, 1997):

$$
K(H)=e^{-\lambda H}
$$


Substituting all this into equation (3.4), and realising that the herbicide treatment will not affect the resistant weeds, yields:

$$
Y=Y_{O}\left\{1-\frac{I \cdot R_{o} \cdot\left[1-S+S \cdot e^{-\lambda H}\right]}{100\left[e^{c t}+\frac{I \cdot R_{o} \cdot\left[1-S+S \cdot e^{-\lambda H}\right]}{A_{W}}\right]}\right\}
$$

The recruitment of seedlings from the seed bank can be described by the following equation (Neve, Norsworthy, Smith, \& Zelaya, 2011):

$$
R_{o}=\frac{W}{\left[1+e^{-\left(\frac{t-t_{0}}{d}\right)}\right]}
$$

Substituting this into equation (3.5) yields:

$$
Y=Y_{O}\left\{1-\frac{I \cdot W \cdot\left[1-S+S \cdot e^{-\lambda H}\right]}{100\left[e ^ { c t } \left[1+e^{\left.\left.-\left(\frac{t-t_{o}}{d}\right)\right]+\frac{I \cdot W \cdot\left[1-S+S \cdot e^{-\lambda H}\right]}{A_{W}}\right]}\right.\right.}\right\}
$$

The portion of the population that is resistant to herbicide treatment will change from generation to generation depending on the selection pressure being applied by the herbicide treatments. Based on work by Gubbins and Gilligan (1999), if there is a relatively constant selection pressure (a) towards herbicide resistance from generation to generation, then the following relationship will hold:

$$
\frac{\partial S}{\partial g}=-a S g
$$

This partial differential equation can be solved by integration to give:

$$
S=S_{o} \cdot e^{\frac{-a g^{2}}{2}}
$$

Substituting this into equation (3.7) and simplifying yields:

$$
Y=Y_{O}\left\{1-\frac{I \cdot W \cdot\left[1-S_{o} \cdot e^{\frac{-a g^{2}}{2}}+S_{o} \cdot e^{\frac{-a g^{2}}{2}-\lambda H}\right]}{100\left[e^{c t}\left[1+e^{\left.\left.-\left(\frac{t-t_{o}}{d}\right)\right]+\frac{I \cdot W \cdot\left[1-S_{0} \cdot e^{\frac{-a g^{2}}{2}}+S_{o} \cdot e^{\frac{-a g^{2}}{2}}-\lambda H\right.}{A_{W}}\right]}\right]\right.}\right\}
$$


There is also evidence that herbicides have a toxic effect on the crop as well. Using the study by Yin et al. (2008) as a guide, and assuming that the toxicity of the herbicide on a crop can be expressed as a polynomial of the form Loss $=a H^{2}-b H$, equation (3.10) can be modified to become:

$$
Y=Y_{O}\left\{1-\frac{I \cdot W \cdot\left[1-S_{0} \cdot e^{\frac{-a g^{2}}{2}}+S_{o} \cdot e^{\frac{-a g^{2}}{2}-\lambda H}\right]}{100\left[e ^ { c t } \left[1+e^{\left.\left.-\left(\frac{t-t_{o}}{d}\right)\right]+\frac{I \cdot W \cdot\left[1-S_{0} \cdot e^{\frac{-a g^{2}}{2}}+S_{o} \cdot e^{\frac{-a g^{2}}{2}} \lambda H\right.}{A_{W}}\right]}\right.\right.}+\mathrm{a} H^{2}-b H\right\}
$$

The seed bank will be dynamic depending on factors such as natural seed mortality, immigration of seeds into the area from other locations via various vectors, emigration of seeds out of the area to other locations via various vectors, the onset of dormancy that prevents germination in the current season, and the breaking of dormancy from previous seasons in the seed bank.

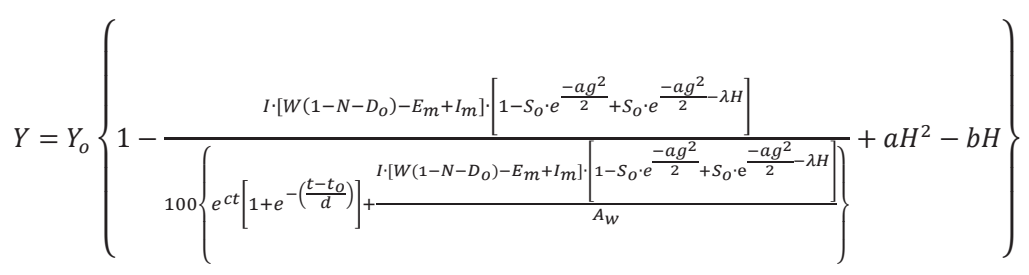

\subsection{Sensitivity Analysis}

The development of transfer functions does not always provide accurate prediction but to provides insight into system behaviours as input parameters change. The sensitivity of the output to these changes can be assessed by differentiating the transfer function equations with respect to the input parameter of interest and assessing the magnitude of the resulting differential equation. For example, the sensitivity of the crop to herbicide weed control is given by differentiating equation (3.12) with respect to the herbicide dose, $\mathrm{H}$ :

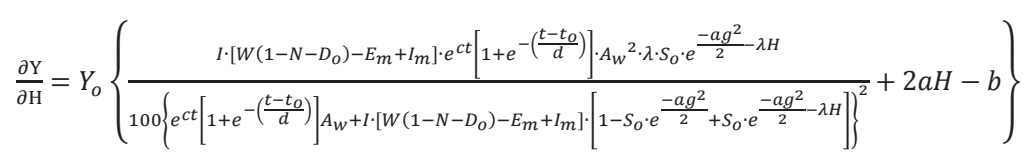

Herbicide resistance in many weed species is becoming more prevalent (Heap, 1997, 2008). Thornby and Walker (2009) simulated continuous summer fallows using 
glyphosate. Their modelling showed that barnyard grass (Echinochloa colona) could become resistant to glyphosate in about 15 years. Validation of their model against paddock history data for glyphosate-resistant population of barnyard grass showed that their model correctly predicted resistance development to within a few years of the real situation.

Selection pressure for genetic traits depends on the initial efficacy of the herbicide to remove susceptible individuals from the population, leaving only the resistant individuals to reproduce. This is reinforced by the adoption of a single herbicide over a long period to sustain the selection pressure on the population.

The transfer function developed in equation (3.12) can also provide some insight in the rate of change of yield potential as a function of weed population generations, hence providing some insights into herbicide resistance. Differentiating equation (3.12) with respect to the generations of weeds gives:

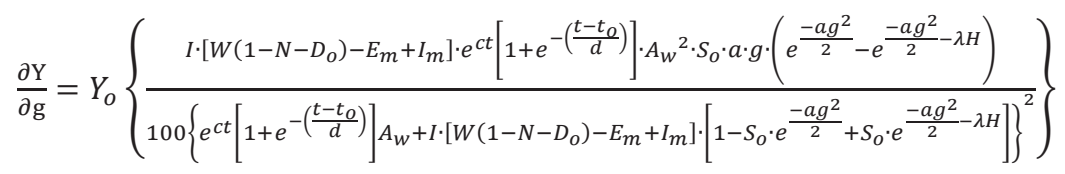

Timeliness of herbicide application is another important consideration in weed management. Herbicide application can be delayed for several reasons, but often it is associated with inclement weather conditions such as wind and rain, both of which impede the opportunity to spray herbicides safely and effectively. If weeds become well established before the crop canopy closes, yield losses can be expected. The sensitivity of yield potential to timeliness can be evaluated by differentiating equation (3.12), with respect to t:

$$
\begin{aligned}
& \frac{d Y}{d t}=Y_{o}\left\{\frac{I \cdot W \cdot\left[1-S_{o} \cdot e^{\frac{-a g^{2}}{2}}+S_{o} \cdot e^{\frac{-a g^{2}}{2}}-\lambda H\right] \cdot c \cdot e^{c t}}{100\left[1+e^{-\left(\frac{t-t_{o}}{d}\right)}+\frac{I \cdot W \cdot\left[1-S_{o} \cdot e^{\frac{-a g^{2}}{2}}+S_{o} \cdot e^{\frac{-a g^{2}}{2}}-\lambda H\right.}{A_{w}}\right]}\right] \\
& \left.\left.-\frac{I \cdot W \cdot\left[1-S_{o} \cdot e^{\frac{-a g^{2}}{2}}+S_{o} \cdot e^{\frac{-a g^{2}}{2}-\lambda H}\right] \cdot e^{c t}\left[1+e^{-\left(\frac{t-t_{o}}{d}\right)}\right]}{100 \cdot \mathrm{d} \cdot\left[1+e^{-\left(\frac{t-t_{o}}{d}\right)}+\frac{I \cdot W \cdot\left[1-S_{o} \cdot e^{\frac{-a g^{2}}{2}}+S_{o} \cdot e^{\frac{-a g^{2}}{2}-\lambda H}\right]}{A_{W}}\right]}\right]^{2}\right\}
\end{aligned}
$$




\subsection{Examples}

Equation (3.12) was coded into a simple cropping system model using the MatLab® software platform. Using data published by Bosnić and Swanton (1997) and Yin et al. (2008) for Rimsulfuron herbicide and assuming: an initially same small resistant population (i.e. $S_{o}=0.9999$ ); a seed mortality rate of $10 \%$ each year; and a slightly positive selection coefficient of $(\mathrm{a}=0.002)$ for herbicide resistance (Baucom \& Mauricio, 2004), the system transfer function was used to analyse the effect of a single herbicide application on crop yield potential. The transfer function was also used to forecast the long-term crop yield potential, if only a single herbicide type was used during this time.

Figure 3.1 shows the expected crop yield response as a function of the herbicide's application rate. Based on the parameters used in this example, there is an optimal active ingredient application rate (i.e. where $\frac{\partial Y}{\partial H}=0$ ) of about $0.009 \mathrm{~kg} \mathrm{ha}^{-1}$, while the maximum rate of crop yield response occurs at about $0.001 \mathrm{~kg} \mathrm{ha}^{-1}$.

The transfer function also predicts that significant herbicide resistance will occur within 15 generations (Figure 3.2), as was also predicted by Thornby and Walker (2009). This is apparent when looking at how the relative crop yield potential reduces along the generations axis in Figure 3.2. After 15 to 20 years of using the same herbicide control system, the model outlined in equation (3.12) suggest that further herbicide application will be ineffectual. Herbicide rotations can forestall the development of a resistant population; however several weed species have developed multiple resistance to several herbicide groups (Owen et al., 2007).

It is possible to visualise the influence of both herbicide application and generational change in a response surface, as shown in Figure 3.3.

The sensitivity of crop yield potential to timeliness can be assessed from equations (3.12) and (3.15). Figure 3.4 depicts the influence of time between crop emergence and weed emergence over crop yield potential.

\subsection{Conclusion}

A growing herbicide resistance problem is already evident in most Australian cropping systems (Broster \& Pratley, 2006; Gill \& Holmes, 1997). There is evidence that glyphosate resistance has already developed in some weed populations (Broster \& Pratley, 2006) and multiple herbicide resistances has been widely reported in several weed species (Kuk, Burgos, \& Talbert, 2000; Owen et al., 2007; Walsh, Powles, Beard, Parkin, \& Porter, 2004; Yu, Cairns, \& Powles, 2007); therefore significant crop yield losses can be expected into the future as weed become more resistant to herbicide management strategies. Alternative weed management strategies that are compatible with no-till cropping systems need to be developed. The next chapter will discuss some of the non-chemical weed control strategies that have been considered in recent time. 


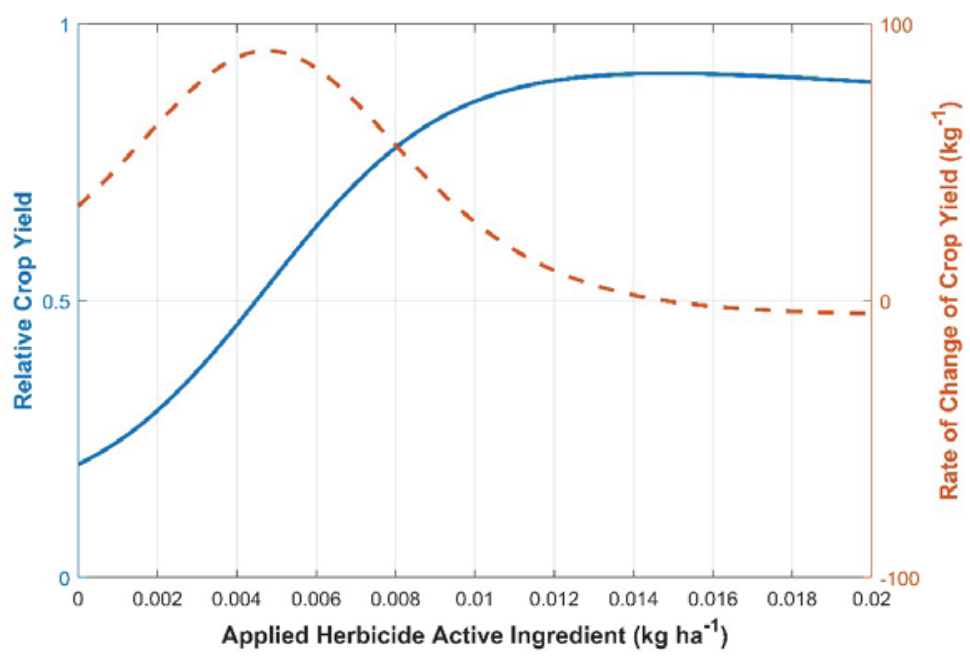

Figure 3.1: Normalised crop yield (blue line) and rate of change of crop yield (orange line) as a function of applied herbicide energy, based equation (3.12).

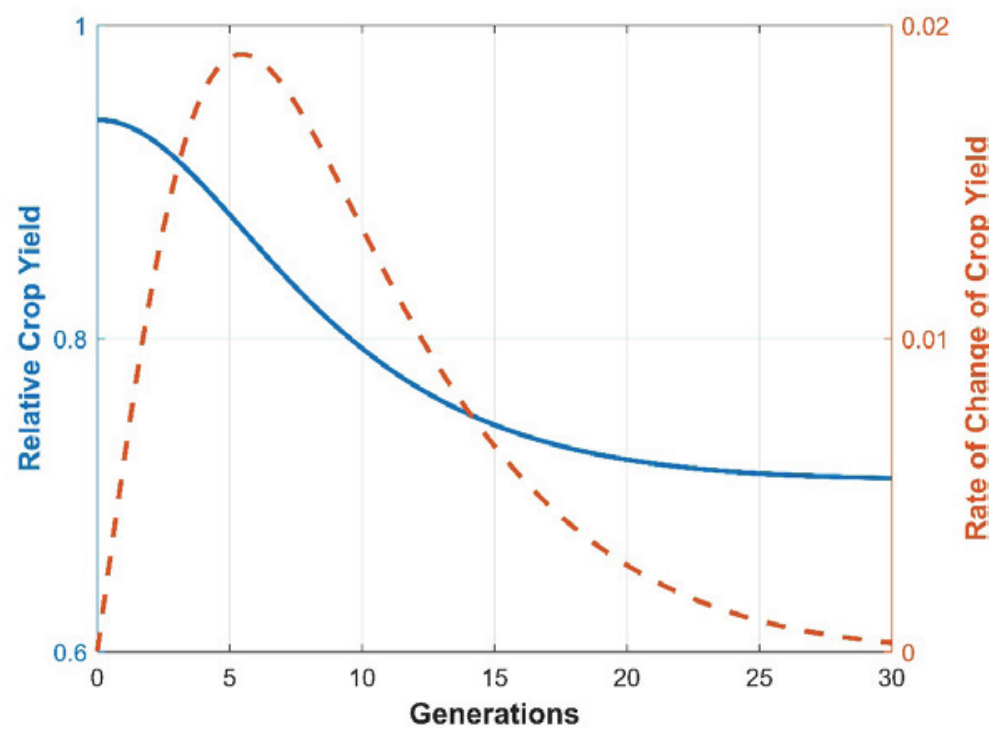

Figure 3.2: Normalised crop yield (blue line) and rate of change of crop yield (orange line) as a function of time (generations of weeds), based on (3.12). 


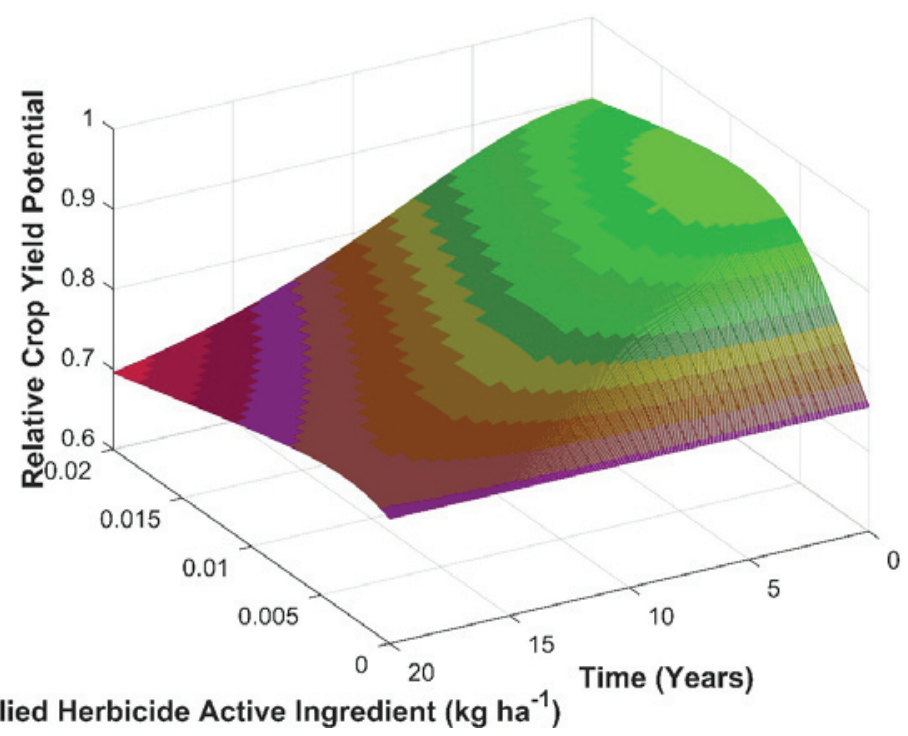

Figure 3.3: Response surface for potential crop yield as a function of both herbicide application and generational change in the weed population.

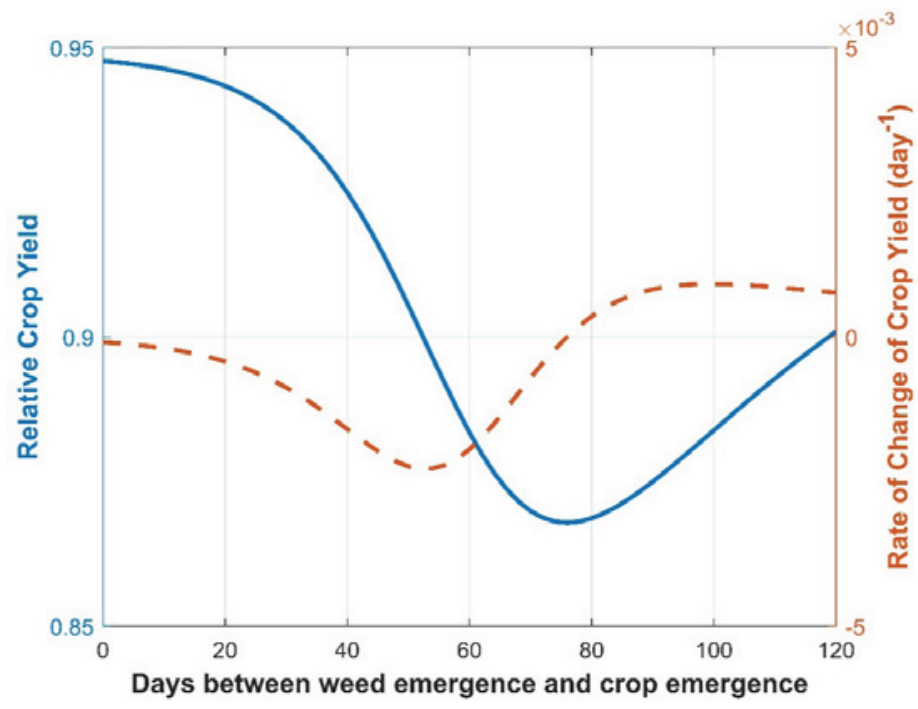

Figure 3.4: Response of crop yield potential to the number of days between weed emergence and crop emergence. 
Table 3.1: Nomenclature used in this chapter.

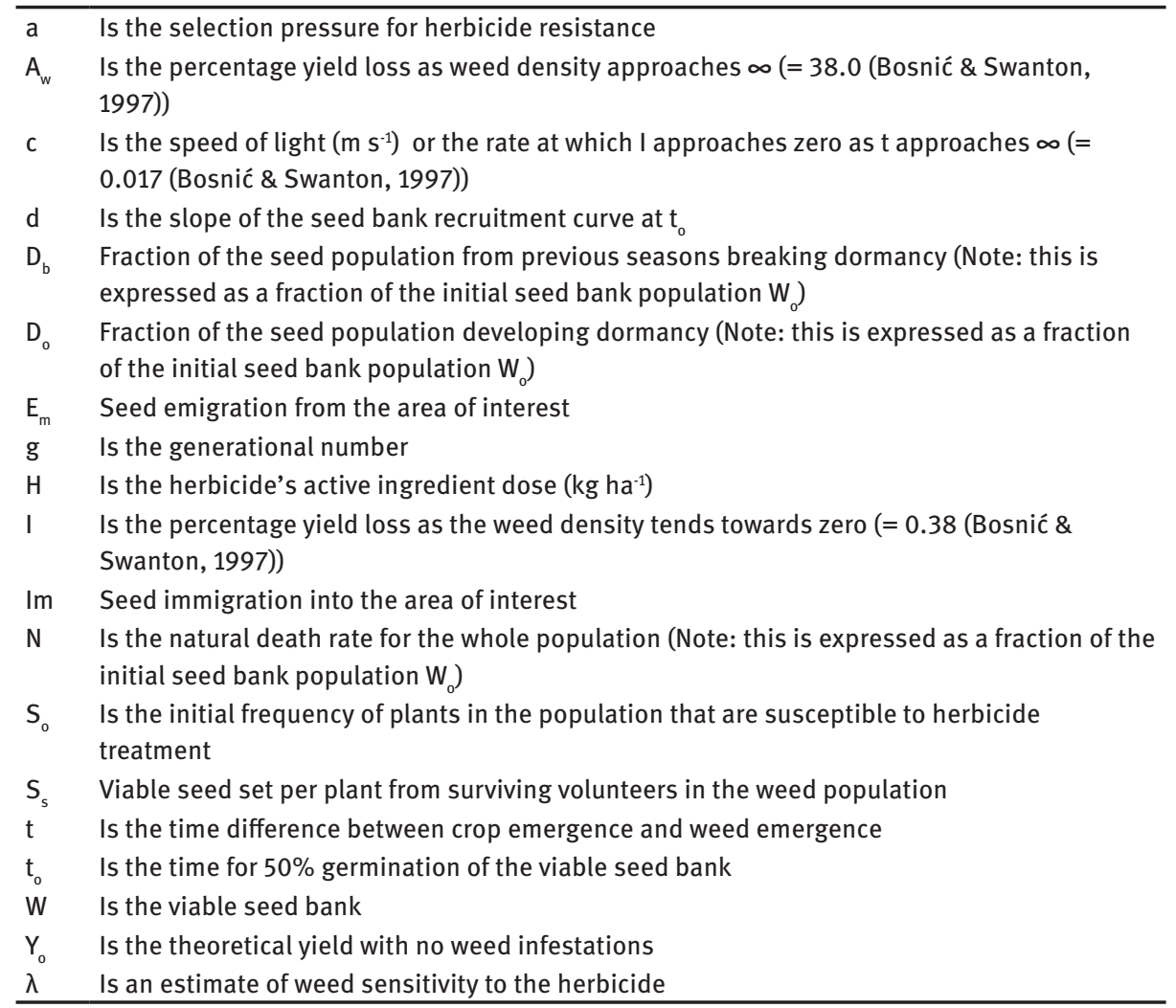

\subsection{References}

Åström, K. J., \& Murray, R. M. (2012). Feedback Systems: An Introduction for Scientists and Engineers. Princeton, New Jersey: Princeton University Press.

Baucom, R. S., \& Mauricio, R. (2004). Fitness costs and benefits of novel herbicide tolerance in a noxious weed. Proceedings of the National Academy of Sciences of the United States of America, 101(36), 13386-13390. doi:10.1073/pnas.0404306101

Bosnić, A. Č., \& Swanton, C. J. (1997). Economic Decision Rules for Postemergence Herbicide Control of Barnyardgrass (Echinochloa crus-galli) in Corn (Zea mays). Weed Science, 45(4), 557-563.

Broster, J. C., \& Pratley, J. E. (2006). A decade of monitoring herbicide resistance in Lolium rigidum in Australia. Australian Journal of Experimental Agriculture, 46(9), 1151-1160.

Cathcart, R. J., \& Swanton, C. J. (2003). Nitrogen management will influence threshold values of green foxtail (Setaria viridis) in corn. Weed Science, 51(6), 975-986. doi:10.1614/p2002-145

Cousens, R., Brain, P., O’Donovan, J. T., \& O’Sullivan, P. A. (1987). The use of biologically realistic equations to describe the effects of weed density and relative time of emergence on crop yield. Weed science (USA).

Gill, G. S., \& Holmes, J. E. (1997). Efficacy of cultural control methods for combating herbicideresistant Lolium rigidum. Pesticide Science, 51(3), 352-358. 
Gubbins, S., \& Gilligan, C. A. (1999). Invasion Thresholds for Fungicide Resistance: Deterministic and Stochastic Analyses. Proceedings: Biological Sciences, 266(1437), 2539-2549. doi:10.2307/1353823

Heap, I. M. (1997). The occurrence of herbicide-resistant weeds worldwide. Pesticide Science, 51(3), 235-243.

Heap, I. M. (2008). International Survey of Herbicide Resistant Weeds. Retrieved from http://www. weedscience.org/in.asp

Kuk, Y. I., Burgos, N. R., \& Talbert, R. E. (2000). Cross- and multiple resistance of diclofop-resistant Lolium spp. Weed Science, 48(4), 412-419.

Mondani, F., Golzardi, F., Ahmadvand, G., Ghorbani, R., \& Moradi, R. (2011). Influence of Weed Competition on Potato Growth, Production and Radiation Use Efficiency. Notulae Scientia Biologicae, 3(3), 42-52.

Neve, P., Norsworthy, J. K., Smith, K. L., \& Zelaya, I. A. (2011). Modelling evolution and management of glyphosate resistance in Amaranthus palmeri. Weed Research, 51(2), 99-112.

Owen, M., Walsh, M., Llewellyn, R., \& Powles, S. (2007). Widespread occurrence of multiple herbicide resistance in Western Australian annual ryegrass (Lolium rigidum) populations. Australian Journal of Agricultural Research, 58(7), 711-718.

Schmidt, C. P., \& Pannell, D. J. (1996). Economic Issues in Management of Herbicide-Resistant Weeds. Research in Agricultural and Applied Economics, 64(3), 301-308.

Smith, R. J. (1976). Circuits, Divices and Systems (3rd ed.). New York: Wiley International.

Thornby, D. F., \& Walker, S. R. (2009). Simulating the evolution of glyphosate resistance in grains farming in northern Australia. Annals Of Botany, 104(4), 747-756. doi:10.1093/aob/mcp152

Walpole, R. E., \& Myers, R. H. (1972). Probability and Statistics for Engineers and Scientists. New York: Macmillan Publishing Co.

Walsh, M. J., Powles, S. B., Beard, B. R., Parkin, B. T., \& Porter, S. A. (2004). Multiple-Herbicide Resistance across Four Modes of Action in Wild Radish (Raphanus raphanistrum). Weed Science, 52(1), 8-13.

Wilson, J. (1988). Changing agriculture: an introduction to systems thinking. Kenthurst [N.S.W.]: Kangaroo Press.

Yin, X. L., Jiang, L., Song, N. H., \& Yang, H. (2008). Toxic Reactivity of Wheat (Triticum aestivum) Plants to Herbicide Isoproturon. Journal of Agricultural and Food Chemistry, 56(12), 4825-4831. doi:10.1021/jf800795v

Yu, Q., Cairns, A., \& Powles, S. (2007). Glyphosate, paraquat and ACCase multiple herbicide resistance evolved in a Lolium rigidum biotype. Planta, 225(2), 499-513. 